\title{
Continuing Professional Development update
}

\section{Revised modular requirement}

The October meeting of the Court of Electors agreed major changes in CPD modular requirements, which will be phased in from 1 April 1999. These will reduce the number of hours required annually, and the modules themselves will be simplified. I hope that these changes will mean the clinicians who hitherto have felt that the existing modular requirements are too large or complex will now feel able to participate in our CPD scheme.

Details will be set out in due course but they are described here in outline. This notice will also appear in the College's Psychiatric Bulletin.

\section{Omission of formal modular requirement for reading, research and personal study (the present Module D)}

This will mean that the total number of hours required each year will be reduced from 150 to 50 hours. Reading/personal study of approximately 2 hours per week will still be recommended but not measured formally as a modular requirement.

\section{There will be two modular requirements (total 50 hours)}

\section{External (20 hours)}

This will include both didactic teaching and participation in workshop-type events (combining the present Modules A and B). Although there will no longer be a separate modular requirement for participatory learning, the paramount importance of this will be emphasised. This module is termed external because its essential component is attendance at events which involve speakers/workshop leaders from outside a clinician's own locality, sometimes but not necessarily at an 'away' venue.

\section{Internal (30 hours)}

This will include educational events, such as case conferences and audit meetings, participation in which is normally confined to staff derived from one's own work locality (the present Module C).

\section{Adoption of a five-year cycle}

This will allow a moving average, thereby introducing a flexibility in allowing for various types of leave that is difficult to achieve in the present oneyear cycle.

\section{Subscriptions}

A review is also currently being undertaken into the subscription arrangements, both with regards to CPD itself and its association with that for Advances in Psychiatric Treatment. 